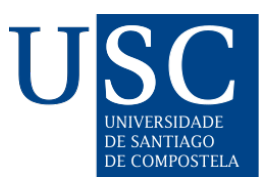

\title{
Imagining the International: Crime, Justice, and the Promise of Community
}

\author{
Christoph R. Schreinmoser \\ Doctorando en Derecho, Universidade da Coruña, España \\ c.schreinmoser@gmx.de
}

En la actualidad, la justicia internacional penal y el Derecho Internacional Penal (DIP) se encuentran en una verdadera encrucijada. Por una parte, la propuesta de ampliar el ámbito de aplicación del DIP a la lucha contra la delincuencia transnacional es cada vez más popular, mientras que, al mismo tiempo, el apoyo internacional a los mecanismos propios de la justicia internacional parece estar perdiendo impulso (Olasolo Alonso, 2017). En ocasiones, esta falta de apoyo se transforma incluso en una hostilidad abierta, como se puso de manifiesto el verano pasado cuando el gobierno estadounidense del Presidente Trump impuso sanciones a la fiscal jefe de la Corte Penal Internacional (CPI), Fatou Bensouda, y a otros funcionarios de la Corte. Aunque este ataque fue inmediatamente seguido por expresiones de apoyo a la CPI por parte de un gran número de Estados, es cuestionable hasta qué punto la Corte será capaz de cumplir su misión de manera coherente a largo plazo sin el apoyo (o al menos una cierta benevolencia) de los EE. UU. Un gran número de voces, especialmente de África, ya están cuestionando la eficacia de la Corte y denunciando su aparente selectividad en la selección de sus casos. En este sentido, Archibugi y Pease (2018) sacan una conclusión devastadora: "[S]i el principal objetivo de la justicia internacional penal era poner fin a la impunidad, aún no se ha logrado. La impunidad por los crímenes internacionales sigue siendo casi absoluta" (p. 204). Tampoco es de esperar que este panorama cambie en un futuro próximo. Esto es especialmente cierto ya que, como afirman acertadamente Cryer, Robinson y Vasiliev (2019), los próximos años serán desafiantes no solo para justicia internacional penal sino para todos los proyectos internacionales debido al aumento global del nacionalismo y el proteccionismo.

Es en estos tiempos tempestuosos y difíciles para el sistema de justicia internacional que se publica Imagining the International: Crime, Justice, and the Promise of Community, la nueva obra de Nesam McMillan. McMillan es doctora en Criminología por la Universidad de Melbourne, Australia. Actualmente es profesora de Criminología Mundial en la Facultad de Ciencias Sociales y Políticas de la misma universidad, donde lleva a cabo investigación y docencia en el ámbito de los daños masivos, la injusticia estructural y el genocidio. Asimismo, ha sido investigadora visitante en la Universidad Libre de Ámsterdam, Países Bajos, y ha realizado estancias de investigación empírica en Ruanda, los Países Bajos y Bélgica.

En Imagining the International la autora cuestiona críticamente algunos de los supuestos fundamentales sobre los conceptos de crimen internacional y justicia global y analiza sus límites 
y potencialidades éticas. Para este análisis, emplea un enfoque interdisciplinario que combina el derecho, la criminología, el humanitarismo, los estudios socio-jurídicos y los estudios culturales. El objetivo de su trabajo es mostrar cómo se conciben ciertas formas de crimen y justicia como internacionales $\mathrm{y}$, por lo tanto, de especial importancia, y exponer las limitaciones de los planteamientos dominantes con respecto a estas categorías. Con este fin, se basa en tres estudios de casos: las reacciones internacionales al genocidio de Ruanda, los debates de la Comisión de Derecho Internacional (CDI) en el marco del proyecto de código de crímenes contra la paz y la seguridad de la humanidad y las representaciones dominantes de la justicia internacional penal.

McMillan describe, en primer lugar, cómo se comprenden las nociones de crimen y justicia internacionales en el discurso autoritativo. Ambos conceptos son presentados como algo estrictamente separado de lo cotidiano, de lo nacional. Los crímenes internacionales, según la autora, se consideran particularmente graves, produciéndose a escala masiva y teniendo repercusiones que transcienden a las personas y la área geográfica directamente afectadas. Como tales, se encuentran en la cima de la jerarquía de crímenes y se dirigen no solo contra las víctimas directas, sino contra "todos nosotros". Esta concepción no es una definición jurídica de esta categoría de delito, como afirma la propia McMillan. De hecho, existe una controversia en el marco de la doctrina del DIP sobre si los crímenes internacionales deben entenderse en un sentido amplio - como todos los crímenes definidos por el derecho internacional - o en un sentido más restringido - requiriendo ciertas características calificadoras (Olasolo Alonso, 2017). Sin embargo, la presentación de los crímenes internacionales como delitos particularmente graves que afectan a toda la humanidad es evocada habitualmente por los actores e instituciones del sistema de justicia internacional penal, como muestra McMillan en su libro con ejemplos demostrativos, y por lo tanto desempeña un papel central en la comprensión general de este concepto. De manera análoga a la idea del crimen internacional, el concepto de la justicia internacional se caracteriza también por su jerarquización y delimitación de lo nacional: se presenta como un ideal humanitario, como no influenciado por la política nacional y como residiendo en la cima de una jerarquía de formas de justicia. El carácter especial de la justicia internacional penal, así la autora, está vinculado a su alteridad constitutiva y a su externalidad a la vida cotidiana. En resumen, el crimen y la justicia internacionales son conceptos que se presentan y conciben como únicos, prioritarios y humanitarios a través de la jerarquización, la espectacularización y la valorización.

McMillan continúa argumentando que esta jerarquización y valorización de los dos conceptos que a primera vista parecen ser una reacción apropiada a la gravedad de los delitos - son procesos socio-jurídicos que también tienen considerables implicaciones negativas. En este sentido, las nociones crean una distancia ética y relacional entre los que sufren y los que no sufren y pueden contribuir a minimizar otras formas de violencia, sufrimiento e injusticia que no se consideran parte de la categoría de crímenes internacionales. Esa dinámica puede observarse incluso dentro de la misma categoría, cuando los grupos de víctimas tratan de que las atrocidades cometidas contra ellos se clasifiquen como genocidio, ya que ese delito se considera peor que los "meros" crímenes de lesa humanidad. Aquí resulta especialmente destacable la crítica de McMillan a las tendencias apropiativas dentro de los conceptos de crimen y justicia internacionales, que describe a partir de las reacciones internacionales al genocidio de Ruanda. La autora detalla cómo se globalizó posteriormente el genocidio haciendo hincapié en sus repercusiones para otros, para la humanidad en su conjunto y no para los propios ruandeses. "Ruanda" se presenta como un acontecimiento mundial, un crimen contra todos nosotros, y como tal, el debate se centra en cómo el Occidente puede evitar que se produzcan más "Ruandas" en el futuro. Esto deja claro que la 
internacionalización de un acto como el genocidio de Ruanda despliega su propia dinámica de poder, a través de la cual se reconceptualizan los sufrimientos y los daños experimentados por personas concretas en momentos y lugares específicos como crímenes contra "nosotros". Parece evidente que este proceso conlleva el riesgo de perder de vista a las víctimas reales y las causas socioeconómicas de la violencia.

En definitiva, Imagining the International representa una valiosa contribución crítica a nuestra comprensión de los conceptos fundamentales de crimen y justicia internacionales. El perspicaz libro muestra que la presentación y la valorización de los dos conceptos como separados de lo cotidiano es un proceso de jerarquización que tiene importantes implicaciones sociales, políticas y jurídicas e influye en la forma en que percibimos el sufrimiento en el mundo. Al hacerlo, nos insta a reflexionar sobre algunos de las nociones básicas de la justicia internacional penal. En tiempos en que el descontento y la desilusión con la justicia internacional es tan grande, incluso dentro de sus partidarios, tales reflexiones son imprescindibles para poder encontrar respuestas a los grandes desafíos que ella y el DIP están enfrentando. Así pues, como bien constata McMillan, es hora de dejar atrás la idealización y valorización de las ideas de crimen y justicia internacionales y de empezar a debatir de manera honesta sus posibilidades y limitaciones.

\section{Información Adicional:}

Título: Imagining the International: Crime, Justice, and the Promise of Community

Autor: McMillan, Nesam

Editorial: Stanford University Press

Año de edición: 2020

Páginas: 224

ISBN: 978-1503612815

\section{REFERENCIAS}

Archibugi, D. y Pease, A. (2018). Crime and Global Justice: The Dynamics of International Punishment. Cambridge: Polity.

Cryer, R., Robinson, D. y Vasiliev, S. (2019). An Introduction to International Criminal Law and Procedure (4⿳亠丷厂 ed.). Cambridge: Cambridge University Press.

Olasolo Alonso, H. (2017). Derecho Internacional Penal, Justicia Transicional y Delitos Transnacionales: Dilemas Políticos y Normativos. Valencia: Tirant lo Blanch. 